\title{
Radiation and Photo-Induced Ionic Polymerization
}

\author{
Koichiro HAYASHI \\ The Institute of Scientific and Industrial Research, Osaka University, \\ Yamadakami, Suita, Osaka 565, Japan.
}

(Received August 8, 1980)

\begin{abstract}
It was established that under dry conditions the radiation-induced polymerizations of styrene and $\alpha$-methylstyrene proceed predominantly through free cationic intermediates. The parallel measurements of electrical conductivity and rate of polymerization were carried out on these monomers. According to eq $1,\left(\tau_{\mathrm{g}}=r^{3} / 3 D r_{\mathrm{c}}\right)$, the estimation of $k_{\mathrm{p}}(+)$ rests on a knowledge of $R_{\mathrm{p}}, \tau$, and $R_{\mathrm{i}}$ at a particular dose rate:
\end{abstract}

$$
R_{\mathrm{p}}=R_{\mathrm{i}} \tau k_{\mathrm{p}}[\mathrm{M}]
$$

where $k_{\mathrm{p}}$ is propagation rate constant and [M] concentration of monomer. $R_{\mathrm{p}}$ values are determined dilatometrically and $R_{\mathrm{i}}$ is based on a $G_{\mathrm{i}}$ value of 0.1 for hydrocarbons. It should be noted that the lifetime of free ions under irradiation at these dose rates is the order of $100 \mathrm{~ms}$ and $k_{\mathrm{p}}$ values of free cationic propagation are very large, as high as $10^{6} \mathrm{M}^{-1} \mathrm{~s}^{-1}$. It was reported the estimation of freeion lifetimes by pulse electrical conductivity measurement based on the principle of the "rotating sector method" was used for the lifetime estimation of intermediates generated by electron irradiation through bimolecular reaction. The estimated lifetimes agreed with those calculated from steady-state conductance.

The initiation mechanism of radiation-induced ionic polymerization of $\alpha$-methylstyrene has been elucidated by the use of pulse radiolysis technique.

KEY WORDS Radiation / Polymerization / Free Ion / Electrical Conductivity / Chain Transfer / Propagation Rate Constant / Pulse Radiolysis / Styrene / $\alpha$-Methylstyrene / Trioxane / Polycondensation / Copolymerization / $\gamma$-Rays / Electron Beam / Hydride Ion Transfer / Ion Radical /

The polymerization of liquid vinyl monomers with high energy radiation has been studied since, at least, 1938. It was shown in the classical studies of Dainton and others that the mechanism was of a free radical nature. However, Davision, Pinner, and Worrall $^{1}$ in 1957 successfully polymerized isobutylene in the liquid state at $-78^{\circ} \mathrm{C}$ with high energy radiation. This was probably the first demonstration that an ionic polymerization could be initiated in the liquid state using high-energy radiation. After considerable research by a number of workers an acceptable picture of this type of radiation polymerization has been developed. ${ }^{2}$

Briefly, it is believed that those few free ions which escape geminate recombination initiate cationic polymerization by a free-ion mechanism. The chains propagate in the same way and eventually terminate either by reaction with an impurity or by combination with the negative species of unknown structure. The yield of free ions is low, about 0.15 per $100 \mathrm{eV}$ and the propagation rate very fast. For these reasons the kinetic chains lengths are very high making the effect of, even minute amounts of, impurity very important. The effect of impurities, believed in general to be water, is compounded due to their constant regeneration by the following type of reaction:

$$
\mathrm{H}_{3} \mathrm{O}^{+}+\mathrm{Y}^{-} \rightarrow \mathrm{H}_{2} \mathrm{O}+\mathrm{YH}
$$

where $\mathrm{H}_{2} \mathrm{O}$ is the impurity and $\mathrm{Y}^{-}$the negative species. The molecular weights of the resulting polymers could be low, in spite of the large kinetic chain length, due to chain transfer to monomer. Although the above discussion suggests positive ion propagation in rare instances, such as with nitroethylene, negative (carbanion) polymerization can 
take place.

In the absence of impurities, mainly achieved by "super" drying techniques, the kinetics are simple; i.e.,

$$
R_{\mathrm{p}}=\frac{k_{\mathrm{p}}(\mathrm{M}) R_{\mathrm{i}}^{1 / 2}}{k_{\mathrm{t}}^{1 / 2}}
$$

where $R_{\mathrm{p}}$ is the rate of polymerization, (M) the monomer concentration, $R_{\mathrm{i}}$ the rate of initiation, $k_{\mathrm{p}}$ and $k_{\mathrm{t}}$ are the rate constants for propagation and termination respectively. The combined use of rate and electrical conductivity studies can yield estimates of $R_{\mathrm{i}}$ and $\tau$ the average lifetime of the ions. In this way the values of $k_{\mathrm{p}}$ can be estimated.

The development of stable carbenium ion salts, which are almost completely dissociated in high dielectric constant solvents, and lead to essentially non-terminating polymerizations of certain vinyl monomer can also give estimates of $k_{\mathrm{p}}$ with "free" carbenium ions. A number of parallel studies have been conducted by Stannett ${ }^{3}$ with a series of vinyl eters. With most of the vinyl ethers, typified by ethyl vinyl ether (EVE), rather good agreement was found between radiation-induced polymerization in bulk and carbenium ion salt initiation in dichloromethane. The initiation mechanism has been elucidated by the use of pulse radiolysis technique. The radiation-induced indirect cationic polymerizations in the presence of suitable additives were investigated.

\section{IONIZATION AND INITIATION ${ }^{4}$}

Under the irradiation of $\gamma$-rays from ${ }^{60} \mathrm{Co}(1.17-$ $1.33 \mathrm{MeV})$ or electron beam $(1-5 \mathrm{MeV})$ from accelerators, the initial distribution of primary active species like ions, ion-radicals, radicals, excited molecules, solvated electron, etc., in a gas follows a pattern very similar to the distribution of the water droplets around the track of charged particles rendered visible and Wilson cloud chamber. It has usually been assumed that the structure of a track in a condensed medium would resemble that of a track in a gas reduced in proportion to the relative densities of the gas and the medium. The isolated clusters of ions distributed like beads on a string along the path of a fast electron.

Figure 1 shows a schematic diagram of the presumed distribution of primary events along the track of a fast electron. The general problem of the

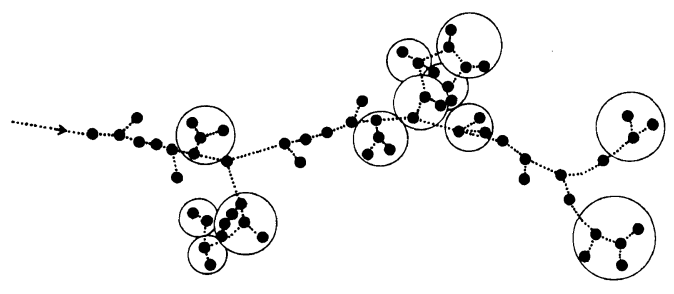

Figure 1. Schematic diagram of the presumed distribution of primary events along the track of a fast electron. ${ }^{4}$

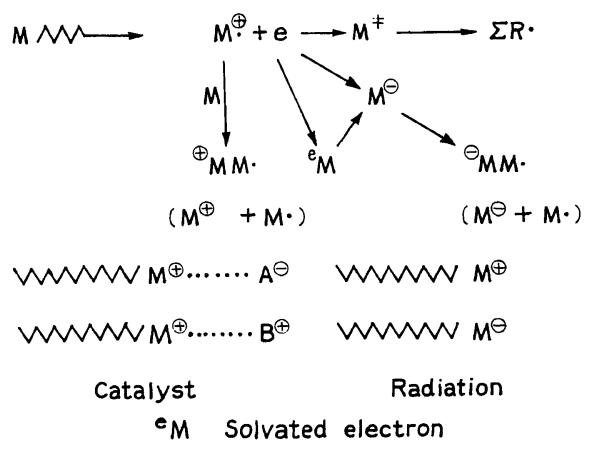

Figure 2. Primary process of radiation-induced polymerization. $^{2}$

reactivity of fragments produced in pairs involving the competition between diffusion and chemical process was discussed. Such considerations indicate that the highly localized distribution of primary active species produced by radiation will lead to some specific factors which may influence the overall reaction kinetics and which may be partly responsible for the formation of molecular product like dimers. However, usually the diffusion of ions take place very rapidly because of this high kinetic energy given by a fast electron.

First, under irradiation, the monomer is ionized, ejecting an electron and forming a cation-radical, $(\mathrm{M} \cdot)^{+}$as shown in Figure 2. The cation-radical and electron may either recombine or separate, depending on the distance of initial separation.

Those that separate behave this way: cationradicals add to other monomers, forming a chain which has a free radical center at one end and a cationic site at the other. Propagation then proceeds independently at each site according to the respective rate constant characteristic of that particular active center.

At the same time, some of the ejected electrons from the initial ionization are captured by mo- 
nomers to form anion-radicals, $(\mathrm{M} \cdot)^{-}$. These anion-radicals then add to other monomers to form a chain with a free radical at one end and an anion site at the other. Propagation again proceeds independently at each active site according to the respective rate constants.

Free ions-those that have become separated by diffusion - have lifetimes of up to 0.1 second at dose rates of 100 kilorad per hour. Those that recombine do so within $10^{-7}$ second to $3 \times 10^{-11}$ second when the distance between species is between 280 and $20 \AA .5$ If the average initial separation is less than $100 \AA$, relatively few ion pairs become free. Thermal recombination of positive holes and trapped electrons in irradiated solids may be regulated by two rather distinct mechanisms. The first possibility is that the electron is activated out of its trap into the conduction band, and thereby becomes "free" with an extended range before undergoing recombination or retrapping. A model of this type with a suitable distribution of trap depths was first suggested for ionic solids, and it has once been applied to explain the radiation-induced conductivity of hydrocarbon polymers. A second mechanism of recombination involves the diffusive motion of the trapped electron, and the author shows that this model predicts the absolute rate of recombination in simple hydrocarbon glasses.

Where the initial separation distance $r$ between the positive hole and trapped electron is less than the distance $r_{\mathrm{c}}$ at which the Coulombic energy $\left(-e^{2} / \varepsilon r_{\mathrm{c}}\right)$ is equal to the thermal energy $k T$, there is a high probability of geminate recombination as given by $1-\exp \left(-r_{\mathrm{e}} / r\right)$. For hydrocarbons with a dielectric constant $\varepsilon \simeq 2$, the value of $r_{\mathrm{c}}$ is $1090 \AA$ at $77 \mathrm{~K}$ and $280 \AA$ at $300 \mathrm{~K}$. In the case of irradiated cyclohexane at room temperature, conductivity results show that the $G$ yield of free ions (those escaping geminate recombination to undergo random recombination in times of $10^{-2} \mathrm{~s}$ at a dose rate of $1 \mathrm{Mradh}^{-1}$ ) is about 0.1 ion per $100 \mathrm{eV}$. This finding is consistent with the results of proton scavenger studies in the radiolysis of cyclohexane which indicate that most ions $(G \simeq 2.6)$ undergo geminate recombination in times $\tau_{\mathrm{g}}$ extending from $3 \times 10^{-11} \mathrm{~s}$ to $10^{-7} \mathrm{~s}$. In geminate recombination, the diffusive motion of the trapped electron back to the positive ion is strongly influenced by the Coulombic field, and the recombination time $\tau_{\mathrm{g}}$ is determined by

$$
\tau_{\mathrm{g}}=r^{3} / 3 D r_{\mathrm{c}}
$$

where $D$ is the total diffusion coefficient. According to eq 1 , the previously mentioned values of $\tau_{\mathrm{g}}$ in liquid cyclohexane $\left(D=2.5 \times 10^{-5} \mathrm{~cm}^{2} \mathrm{~s}^{-1}\right)$ correspond to a distribution of $r$ distances between 19 and $280 \AA$ with an average distance $\langle r\rangle$ of about $50 \AA$. It must be emphasized that the separation distance $r$ is only meaningful after the electron is trapped. An electron of thermal energy $k T$ has a de Broglie wavelength of $70 \AA$ at $300 \mathrm{~K}$ and $150 \AA$ at $77 \mathrm{~K}$, so this measure of uncertainty in position for a mobile electron may indeed be related to the average separation distance achieved in condensed systems before trapping or attachment to solute molecules.

In a hydrocarbon glass at $77 \mathrm{~K}\left(r_{\mathrm{c}}=1090 \AA\right)$, the low rate of recombination prevents the formation of a stationary-state concentration of ions and electrons, and, under these circumstances, it is inappropriate to distinguish between free ions and ions undergoing geminate recombination. For low total doses, therefore, it can be assumed that ionic recombination will occur over the range of initial separation distances $\left(r<r_{\mathrm{c}}\right)$, and it is possible to calculate the relevant time scale.

The initiation mechanism of radiation-induced ionic polymerization of $\alpha$-methylstyrene has been elucidated by the use of pulse radiolysis technique. The samples were irradiated with pulses of $15 \mathrm{MeV}$ electrons using the linear accelerator of the HahnMeitner-Institute. An electron pulse with a total duration of $10 \mathrm{~ns}$ was applied for this experiment. Pulse radiolysis study of $\alpha$-methylstyrene $(M)$ in dichloroethane (S) was carried out at room temperature. In this solvent negatively charged species are efficiently transformed to stable negative ion $\left(\mathrm{Cl}^{-}\right)$and positively charged intermediated can easily be detected.

$$
\begin{aligned}
& \mathrm{S} \sim \mathrm{S}^{+}+\mathrm{e}^{-} \\
& \mathrm{e}^{-}+\mathrm{S} \longrightarrow \cdot \mathrm{S}_{1}+\mathrm{Cl}^{-} \\
& \mathrm{S}^{+}+\mathrm{M} \longrightarrow \mathrm{S}+\mathrm{M}^{+} \\
& \mathrm{S}^{+}+(\mathrm{M})_{2} \longrightarrow \mathrm{S}+(\mathrm{M})_{2}^{+} \\
& \text {Associated dimer (2d) } \\
& (\mathrm{M})_{2}^{+} \longrightarrow(\mathrm{M}-\mathrm{M})^{+} \quad \text { Bonded dimer } \\
& \mathrm{M}^{+}+\mathrm{M} \longrightarrow(\mathrm{M})_{2}^{+}
\end{aligned}
$$




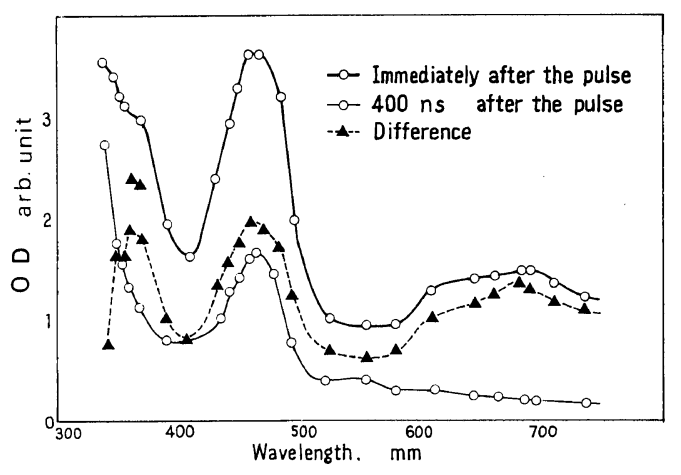

Figure 3. Absorption spectra obtained by irradiating a solution of $\alpha$-methylstyrene in dichloroethane $\left(5 \times 10^{-3} \mathrm{M}\right)$ with a $50 \mathrm{~ns}$ pulse of $15 \mathrm{MeV}$ electrons: ${ }^{42}$ (a) - - , immediately after the pulse; (b) -,$- 400 \mathrm{~ns}$ after the pulse; (c) - $\mathbf{\Delta}-$, difference (a) -(b); dose per pulse, $2.5 \times 10^{3} \mathrm{rad}$; temp, room temperature.

Figure 3 shows the spectra of intermediates obtained immediately after a $50 \mathrm{~ns}$ pulse irradiation and $400 \mathrm{~ns}$ later. The absorption at the maximum at $690 \mathrm{~nm}$ which is ascribed to the monomer radical cation $\left(\mathrm{M}^{+}\right)$decays according to a first-order law $\left(\tau_{1 / 2}=0.3 \mu \mathrm{s}\right)$. The absorption at the maximum at $460-475 \mathrm{~nm}$ decays in a more complicated manner. The semilogarithmic plot exhibits an initial curvature followed by a linear decay indicating the existence of two different species. The difference spectrum (c) in Figure 3 shows three peaks at $355 \mathrm{~nm}, 460-475 \mathrm{~nm}$, and $690 \mathrm{~nm}$. The peaks at $355 \mathrm{~nm}$ and $690 \mathrm{~nm}$ may be attributed to the absorption of the monomer radical cation $\mathrm{M}^{+}$ based on the comparison with the spectra of $\mathrm{M}^{+}$ reported previously. It is assumed that the rapidly decaying absorption at $460-475 \mathrm{~nm}$ may be correlated to the associated dimer $(\mathrm{M})_{2}^{+}$which is formed by reaction (2d). Additional experiments with ps pulses yielded that an absorption at $460 \mathrm{~nm}$ is observable already after a $30 \mathrm{ps}$ pulse. Thus, it appears to be highly probable that the associated dimer is formed very rapidly from ground state dimer $(\mathrm{M})_{2}$ and that the associated dimer is the precursor of the bonded dimer (2d). At low monomer concentration $6.7 \times 10^{-4} \mathrm{M}$, the formation process of $(M)_{2}^{+}$, eq $2 \mathrm{f}$, was observed. On the other hand, irradiation of bulk $\alpha$-methylstyrene yielded only a spectrum exhibiting the absorption of dimer but not absorption due to $\mathrm{M}^{\dagger}$.

\section{PROPAGATION AND $k_{\mathrm{p}}$}

Under the action of ionizing radiation on monomeric systems, several kinds of active species are formed as shown in Figure 2. Radical, cationic or anionic polymerization reactions are initiated through such active species as radicals, ion-radicals, cations, (including protonated monomer $\mathrm{HM}^{+}$), anions, and excited molecules, etc. The reactions which take place depend on the polymerization conditions, such as the state of the system, the nature of monomer, polymerization temperature, and the effect of additives.

In comparison with polymerization by catalysts, the characteristics of radiation-induced polymerization can be enumerated as follows.

i) Coexistence of radical and ionic polymerization.

ii) Propagation by free ions.

iii) Contribution of ion-radical to the initiation reaction. There is much interest in the mechanism of radiation-induced ionic polymerization, because the relative disposition and reactivity of the ions during propagation may differ in a fundamental way from the situation in catalystic studies where, for the most part, the active propagating ends are closely assiciated with inactive counter-ions. On the other hand in radiation-induced polymerization, the propagation proceeds by free ions.

However, the ionic species are scavenged easily by traces of impurities such as water. Therefore, until 1957 almost all studies of radiation-induced polymerization pointed to free radical intermediates as the active species.

$$
\begin{gathered}
m \mathrm{M}^{+}+\mathrm{M} \rightarrow m \mathrm{MM}^{+} \\
\mathrm{MM}^{+}+\left(\mathrm{H}_{2} \mathrm{O}\right)_{n} \rightarrow m \mathrm{MM}(-\mathrm{H})+\mathrm{H}_{3}^{+} \mathrm{O}\left(\mathrm{H}_{2} \mathrm{O}\right)_{n-1}
\end{gathered}
$$

Various aspects of radiation-induced radical polymerization have been reviewed by Chapiro. ${ }^{4}$

As was mentioned above, a cationic mechanism was proposed in 1958 by several investigators for polymerization of styrene. On the other hand, in the cationic polymerization of $\alpha$-methylstyrene a large increase of the polymer yield through rigorous drying of monomer was reported and this drying technique was applied to styrene several years later.

Metz et al. ${ }^{6}$ reported some preliminary results of rate enhancement after a silica gel treatment. Hirota 
et al..$^{7}$ also recorded polymerization rates for styrene $(G(-M)=1550)$ greater than the earlier data in the literature. Through the use of sodium-potassium alloy, Ueno et al. obtained a further increase in the rate, $G(-M)=14,000$. Recent improvement in the drying of styrene by sodium-potassium alloy or barium oxide, has resulted in remarkably increased rate of polymerization and the $G$ value for monomer consumption, $G(-M)$. For instance, the following $G(-M)$ values at a dose rate of $1.9 \times 10^{5} \mathrm{radh}^{-1}$ have been reported; normal drying $240,{ }^{9} 260,{ }^{10}$ sodium-potassium alloy, $34,400,{ }^{11}$ barium oxide $100,000^{12}$ and silica gel $150,000 .^{13}$

More recently it was established that under dry. conditions polymerization proceeds predominantly through ionic intermediates. Evidence of a cationic mechanism was obtained from the effects of additives and from the magnitude of the reactivity ratios in the copolymerization.

It was established that the radiation-induced polymerization of several monomers in the liquid state is subjected to retardation by very low concentrations of cationic scavengers such as water and ammonia, and the efficiency of the retardationdepends on the proton affinity of the scavenger as shown in Table I.

Table I. $^{19}$ Effects of proton scavengers on radiation-induced polymerization of styrene ${ }^{a}$

\begin{tabular}{lccr}
\hline Scavenger & $\begin{array}{c}\text { Conversion } / \\
(0.2 \mathrm{Mrad})\end{array}$ & $M_{n}$ & $G(-M)$ \\
\hline $\mathrm{H}_{2} \mathrm{O} \leqq 0.1 \mathrm{ppm}$ & 27.2 & 50,400 & 13,600 \\
$\mathrm{H}_{2} \mathrm{O}>10 \mathrm{ppm}$ & 1.1 & 49,000 & 550 \\
$\mathrm{NH}_{3} \sim 3 \times 10^{-3} \mathrm{M}$ & 0.13 & - & 65 \\
\hline
\end{tabular}

a Retardation and proton affinity,

$\mathrm{N}\left(\mathrm{CH}_{3}\right)_{3}>\mathrm{NH}_{3}>\mathrm{C}_{2} \mathrm{H}_{5} \mathrm{OC}_{2} \mathrm{H}_{5}>\mathrm{H}_{2} \mathrm{O}$.

On the other hand, in an attempt to elucidate the reaction mechanism, the copolymerization of styrene (St) with $\alpha$-methylstyrene ( $\alpha$-MeSt) was carried out with the results shown in Figure 4. The monomer reactivity ratios (a) are estimated to be $r_{1}(\mathrm{St})=0.25 \pm 0.25, r_{2}(\alpha-\mathrm{MeSt})=8.5 \pm 4.0$ in a "dry" system, while in a "wet" system $r_{1}(\mathrm{St})=2.2 \pm 0.2$, $r_{2}(\alpha-\mathrm{MeSt})=0.6 \pm 0.2$. According to Tobolsky and Boudreau, the reactivity ratios (a) are $r_{1}(\mathrm{St})=10.5 \pm 0.5, \quad r_{2}(\alpha-\mathrm{MeSt})=0.08 \pm 0.02$ in the sodium-tetrahydrofuran system at $0^{\circ} \mathrm{C}$, and

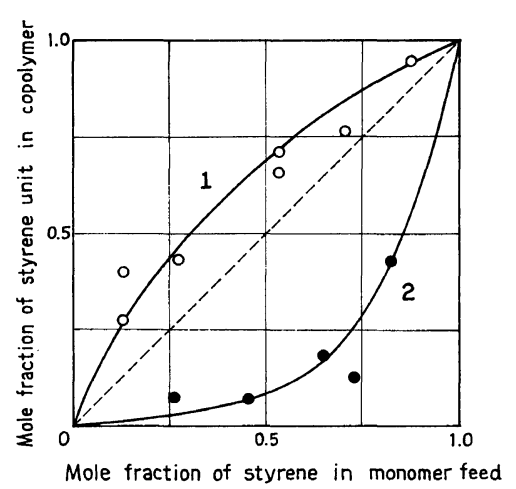

Figure 4. Copolymerization of styrene and $\alpha$-methylstyrene: ${ }^{19} \mathrm{O}, \mathrm{CaH}_{2}$ dried (water $\sim 10^{-3} \mathrm{M}$ ); $\mathrm{O}, \mathrm{Na}-\mathrm{K}$ dried; $1, r_{1}(\mathrm{St})=2.2 \pm 0.2$ and $r_{2}(\alpha-\mathrm{MSt})=0.6 \pm 0.2 ; 2, r_{2}$ $(\mathrm{St})=0.25 \pm 0.25$ and $r_{2}(\alpha-\mathrm{MSt})=8.5 \pm 4.0$; temp, $0^{\circ} \mathrm{C}$; dose rate, $3800 \mathrm{r} \mathrm{min}^{-1}$.

$r_{1}=0.54 \pm 0.04, \quad r_{2}=3.6 \pm 0.1 \quad$ in the titanium tetrachloride-toluene sytem at $0^{\circ} \mathrm{C}$. As monomer reactivity ratios for radical polymerization, they were calculated by the $Q$ and $e$ scheme (b) and estimated to be $r_{1}(\mathrm{St})=3.2, r_{2}(\alpha-\mathrm{MeSt})=0.2$. These results indicate that the mechanism is cationic in a "dry" system and radical in a "wet" system. In the copolymerization of styrene with isobutyl vinyl ether (IBVE), the ratios $r_{1}(\mathrm{St})=0.3 \pm 0.3$ and $r_{2}$ $($ IBVE $)=10.0 \pm 4.0$ are obtained for the "dry" system, while $r_{1}(\mathrm{St})=17.0 \pm 0.8$ and $r_{2}$ $($ IBVE $)=0.1 \pm 0.1$ apply to the "wet" system. The results are understandable in terms of a cationic mechanism, because it is well known that isobutyl vinyl ether is much more sensitive to cationic catalysts than styrene.

Radiation-induced ionic addition polymerization proceeds via a chain reaction involving the three major elementary steps of initiation, propagation, and termination. These elementary steps can be written schematically as follows. ${ }^{14}$

Initiation

$$
\begin{gathered}
\text { Monomer } \mathrm{M} \sim \rightarrow \mathrm{M}^{+}+\mathrm{M}^{-} \\
m \mathrm{M}^{+}+\mathrm{M} \stackrel{k_{\mathrm{ic}}}{\longrightarrow} \cdot \mathrm{MM}^{+} \\
m \mathrm{M}^{-}+\mathrm{M} \stackrel{k_{\mathrm{ia}}}{\longrightarrow} \cdot \mathrm{MM}^{-} \\
R_{\mathrm{i}}=\frac{I G_{\mathrm{i}}}{100 N}
\end{gathered}
$$


where $R_{\mathrm{i}}$ is the rate of initiation, $G_{\mathrm{i}}$ is the $100 \mathrm{eV}$ yield of free ions capable of homogeneous initiation and $N$ is Avogadro's number.

\section{Propagation}

$$
\begin{gathered}
\sim \mathrm{M}^{+}+\mathrm{M} \stackrel{k_{\mathrm{pc}}}{\longrightarrow} \sim \mathrm{MM}^{+} \\
\sim \mathrm{M}^{-}+\mathrm{M} \stackrel{k_{\mathrm{pa}}}{\longrightarrow} \sim \mathrm{MM}^{-} \\
R_{\mathrm{p}}=\left(k_{\mathrm{pc}}+k_{\mathrm{pa}}\right)\left[\sim \mathrm{M}^{+}\right][\mathrm{M}]
\end{gathered}
$$

since the concentration of the anions formed by irradiation should be equivalent to that of the cations. $\sim \mathrm{M}^{+}$and $\sim \mathrm{M}^{-}$represent the growing cation and anion respectively, and $R_{\mathrm{p}}$ is the rate of propagation.

Termination

$$
\begin{gathered}
m \mathrm{M}^{+}+\sim \mathrm{M}^{-} \stackrel{k_{\mathrm{t}}}{\longrightarrow} \text { Polymer } \\
R_{\mathrm{t}}=k_{\mathrm{t}}\left[\sim \mathrm{M}^{+}\right]\left[\sim \mathrm{M}^{-}\right] \\
=k_{\mathrm{t}}\left[\sim \mathrm{M}^{+}\right]^{2}
\end{gathered}
$$

where $R_{\mathrm{t}}$ is the rate of termination.

Assuming the stationary-state treatment to be applicable to the system,

$$
R_{\mathrm{i}}=k_{\mathrm{t}}\left[m \mathrm{M}^{+}\right]^{2}
$$

The consumption of monomer is practically limited to the propagation step, so that the overall reactions rate $R$ is

$$
\begin{aligned}
R=R_{\mathrm{p}} & =\left(k_{\mathrm{pc}}+k_{\mathrm{pa}}\right)\left[m \mathrm{M}^{+}\right][\mathrm{M}] \\
& =\left(k_{\mathrm{pc}}+k_{\mathrm{pa}}\right) k_{\mathrm{t}}^{-1 / 2} R_{\mathrm{i}}^{1 / 2}[\mathrm{M}]
\end{aligned}
$$

From the definition of $\tau$ as the mean lifetime in the stationary state,

$$
\begin{aligned}
& \tau=\frac{\left[m \mathrm{M}^{+}\right]}{R_{\mathrm{i}}}=\left(\frac{1}{R_{\mathrm{i}} k_{\mathrm{t}}}\right)^{1 / 2} \\
& R_{\mathrm{p}}=\left(k_{\mathrm{pc}}+k_{\mathrm{pa}}\right) \tau R_{\mathrm{i}}[\mathrm{M}]
\end{aligned}
$$

The kinetic chain length $v$ and the $100 \mathrm{eV}$ yield of the monomer disappearance $G(-M)$ are given by

$$
\nu=\left(k_{\mathrm{pc}}+k_{\mathrm{pa}}\right)[\mathrm{M}] \tau
$$

and

$$
G(-M)=\left(k_{\mathrm{pc}}+k_{\mathrm{pa}}\right)[\mathrm{M}] \tau G_{\mathrm{i}}
$$

In the case of the radiation-induced ionic polymerization of styrene in bulk, $k_{\mathrm{pc}}>k_{\mathrm{pa}}$ because of experimental support for the cationic polymerization mechanism as mentioned previously. The propagation rate constant $k_{\mathrm{p}}$ has been de-

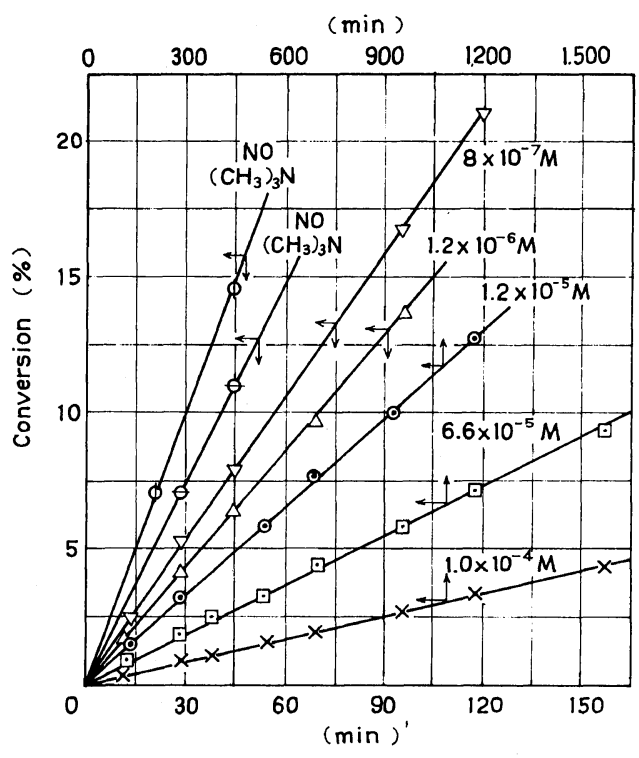

Figure 5. Effect of added $\left(\mathrm{CH}_{3}\right)_{3} \mathrm{~N}$ on polymerization of styrene; temp, $30^{\circ} \mathrm{C}$; dose rate, $2.42 \times 10^{14} \mathrm{eV} \mathrm{g}^{-1} \mathrm{~s}^{-1}$.

termined independently in two different ways; one by the kinetic method in the presence of cation scavenger and the other by direct determination using electrical conductivity methods.

The addition of trimethylamine causes a strong retardation; it is shown in Figure 5, that the rate of polymerization is highly sensitive to a concentation of amine greater than $10^{-6} \mathrm{M}$. At trimethylamine concentrations greater than $10^{-4} \mathrm{M}$, almost the entire ionic contribution to the polymerization is suppressed, for the rate is then characteristic of the residual free-radical process.

The propagation reaction and the scavenging reaction are expressed as

$$
\begin{gathered}
m \mathrm{M}^{+}+\mathrm{M} \stackrel{k_{\mathrm{p}}}{\longrightarrow} \sim \mathrm{MM}^{+} \\
m \mathrm{M}^{+}+\mathrm{N}\left(\mathrm{CH}_{3}\right)_{3} \stackrel{k_{\mathrm{r}}}{\longrightarrow} \sim \mathrm{M}+\mathrm{HN}^{+}\left(\mathrm{CH}_{3}\right)_{3}
\end{gathered}
$$

The application of the equation

$$
\frac{1}{G(-M)}=\frac{k_{\mathrm{r}}[\text { amine }]}{G_{\mathrm{i}} k_{\mathrm{p}}[\mathrm{M}]}
$$

to the results of Figure 5 is somewhat uncertain because of the contribution of the free-radical polymerization at high amine concentration. Nevertheless it is possible to obtain an order-ofmagnitude estimate of $k_{\mathrm{p}}$ from the data. Assuming 
that $G_{\mathrm{i}}$, the yield of initiations, is 0.1 and that $k_{\mathrm{r}}$, the rate constant for retardation, is $8.4 \times 10^{9} \mathrm{M}^{-1} \mathrm{~s}^{-1}$, then $k_{\mathrm{p}}$ is evaluated as $4 \times 10^{8} \mathrm{M}^{-1} \mathrm{~s}^{-1}$, which is throught to be an upper limit.

This value is considerably greater than those obtained in conventional cationic polymerization, in which the active species are believed to consist mainly of thermodynamically stable ion pairs. The large $k_{\mathrm{p}}$ value is attributed to a characteristic iondipole reaction for the free-ion propagation process and also by the considerable freedom of the growing end of a free ion in comparison with that of an ionpair end.

The presence of free ions is most directly demonstrated through measurements of electrical conductivity, which has been recently applied to the determination of ionic yields.

The mean lifetimes of the charge carriers at different dose rates, as calculated from electrical conductivity, are given as $94 \mathrm{~ms}$ for cyclohexane, $180 \mathrm{~ms}$ for styrene, $200 \mathrm{~ms}$ for $\alpha$-methylstyrene, and $160 \mathrm{~ms}$ for isobutyl vinyl ether at the dose rate of $10^{14} \mathrm{eV} \mathrm{ml}^{-1} \mathrm{~s}^{-1}$.

As already mentioned, impurities play an important role in the termination reaction of free-ion propagation, and so the impurity cation formed by the termination reaction plays a major role as charge carrier. The electrical conductivity depends on the square root of the dose rate which means that the ions undergo random bimolecular recombination. In the absence of termination by means of an impurity, the rate of polymerization would be expected to show a similar dose-rate dependence. Recent work shows that $G(-M)$ is as large as 600,000 , and the rate of polymerization depends on the 0.62 power of the dose rate (Figure 6), suggesting that some of the propagating free ions are still undergoing termination by impurities, even in rigorously dried samples.

By means of electrical conductivity ${ }^{21}$ measurements, a kinetic study of radiation-induced polymerization by free ions was made for the purpose of estimating the rate constant $k_{\mathrm{p}}$. The stationary-state equations for chain termination and charge neutralization in the presence of an impurity $X$ are as follows.

$$
\begin{aligned}
R_{\mathrm{i}} & =k_{\mathrm{t}}\left[\sim \mathrm{M}^{+}\right]\left[\mathrm{Y}^{-}\right]+k_{\mathrm{tx}}\left[\sim \mathrm{M}^{+}\right][\mathrm{X}] \\
R_{\mathrm{i}} & =k_{\mathrm{t}}\left[m \mathrm{M}^{+}\right]\left[\mathrm{Y}^{-}\right]+k_{\mathrm{t}}\left[\mathrm{X}^{+}\right]\left[\mathrm{Y}^{-}\right]
\end{aligned}
$$

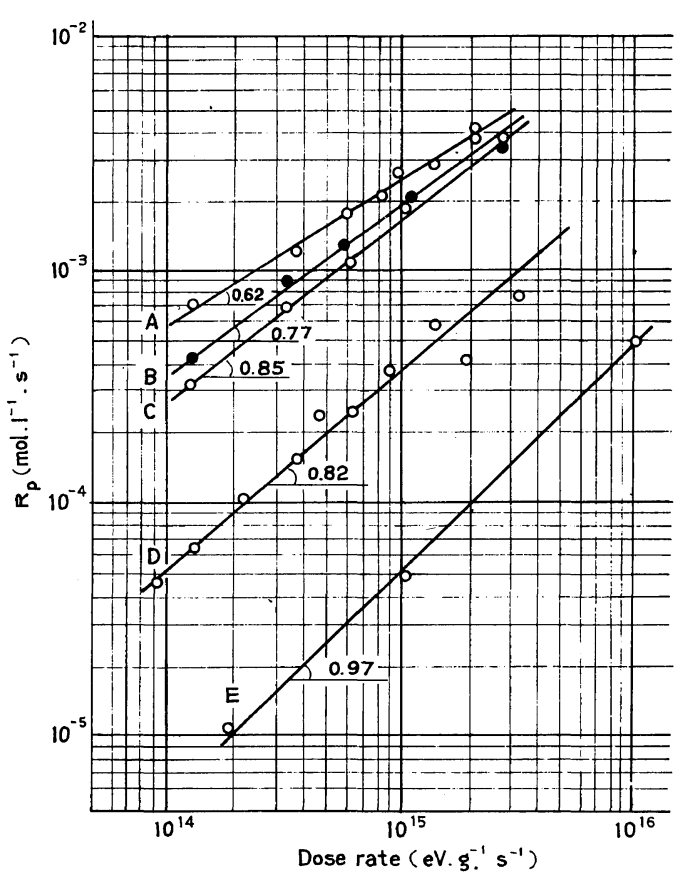

Figure 6. Dose-rate dependence of rate of polymerization styrene at $15^{\circ} \mathrm{C}:{ }^{20} \mathrm{E},\left(\mathrm{CH}_{3}\right)_{3} \mathrm{~N}, 10^{-5} \mathrm{M}$.

where $\left[\sim \mathrm{M}^{+}\right]$represents the concentration of the propagating cation an $\left[\mathrm{Y}^{-}\right]$is of the total negative ion concentration. The identity

$$
k_{\mathrm{tx}}\left[\sim \mathrm{M}^{+}\right][\mathrm{X}]=k_{\mathrm{t}}\left[\mathrm{X}^{+}\right]\left[\mathrm{Y}^{-}\right]
$$

is implied by these equations and obviously conforms to a stationary-state assumption for $\left[\mathrm{X}^{+}\right]$:

$$
\begin{gathered}
{\left[m \mathrm{M}^{+}\right]+\left[\mathrm{X}^{+}\right]=\left[\mathrm{Y}^{-}\right]} \\
{\left[\mathrm{Y}^{-}\right]=\left(\frac{R_{\mathrm{i}}}{k_{\mathrm{t}}}\right)^{1 / 2}}
\end{gathered}
$$

whence

$$
R_{\mathrm{p}}=\frac{R_{\mathrm{i}} k_{\mathrm{p}}[\mathrm{M}]}{\left\{\left(R_{\mathrm{i}} k_{\mathrm{t}}\right)^{1 / 2}+k_{\mathrm{tx}}[\mathrm{X}]\right\}}
$$

A quantitative treatment of this effect can be carried through on the basis of eq 28 by using suitable numerical values for the rate constants $k_{\mathrm{p}}$, $k_{\mathrm{t}}$, and $k_{\mathrm{tx}}$; the results are presented graphically in Figure 7. The curve plotted in this figure shows that as the amount of impurity increases, the absolute value of $R_{\mathrm{p}}$ decreases and the exponent $n=0.62$ corresponds to a behavior intermediate between. 


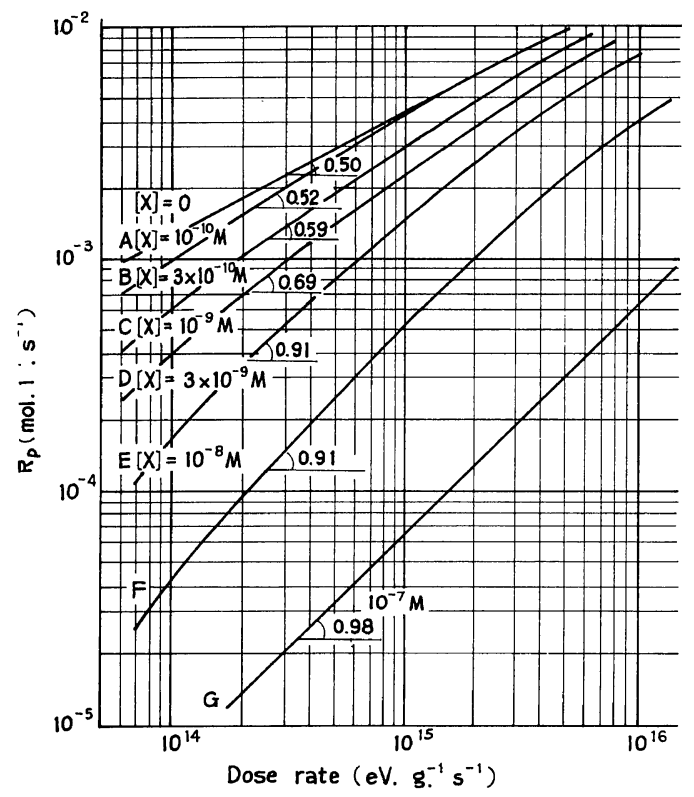

Figure 7. Calculated dose-rate dependence of $R_{\mathrm{p}}$ for styrene as a function of impurity concentration: ${ }^{22}$ $G_{\mathrm{i}}=0.1, k_{\mathrm{t}}=2 \times 10^{11} \mathrm{M}^{-1} \mathrm{~s}^{-1} ; k_{\mathrm{tx}}=10^{10} \mathrm{M}^{-1} \mathrm{~s}^{-1}$; $k_{\mathrm{p}}=5 \times 10^{6} \mathrm{M}^{-1} \mathrm{~s}^{-1}$.

those of curves $\mathrm{C}$ and $\mathrm{D}$ and therefore implies an impurity concentration between $3 \times 10^{-10}$ and $3 \times 10^{-9} \mathrm{M}$ on the basis of these calculations.

Equation 28 may be rewritten in the form

$$
R_{\mathrm{p}}=R_{\mathrm{i}} \tau^{\prime} k_{\mathrm{p}}[\mathrm{M}]
$$

where $\tau^{\prime}$ is defined by the relation

$$
\frac{1}{\tau^{\prime}}=\frac{1}{\tau}+\frac{1}{\tau_{\mathrm{s}}}
$$

and

$$
\tau_{\mathrm{s}}=\frac{1}{k_{\mathrm{tx}}[\mathrm{X}]}
$$

This $\tau^{\prime}$ is the mean lifetime of the propagating ion subject to two competitive termination reactions with independent characteristic lifetimes $\tau$ and $\tau_{\mathrm{s}}$. In the calculations shown in Table III, the $R_{\mathrm{p}}$ values are taken from our results; $\tau$, determined from electrical conductivity, is used instead of $\tau^{\prime}$, and the $R_{\mathrm{i}}$ values are based upon a $G_{\mathrm{i}}$ value of 0.1 .

The measurement of radiation-induced electrical conductivity has established in the presence of free ions. ${ }^{15,16}$ It has been found that the yield of free ions, $G_{\mathrm{i}}$, at room temperature for hydrocarbons

\begin{tabular}{|c|c|c|c|}
\hline Dose rate $/ \mathrm{eV} \mathrm{ml}^{-1} \mathrm{~s}^{-1}$ & $10^{13}$ & $10^{14}$ & $10^{15}$ \\
\hline Cyclohexane & 320 & 94 & 33 \\
\hline Styrene & 710 & 180 & 47 \\
\hline$\alpha$-Methylstyrene & 670 & 220 & 60 \\
\hline Isobutyl vinyl ether & 650 & 160 & 42 \\
\hline
\end{tabular}

Table II. Calculated lifetimes $\tau$ of charge carriers in irradiated liquids $(\mathrm{ms})^{18}$

Table III. Rate constant of radiation-induced polymerization of styrene ${ }^{17}$

\begin{tabular}{lll}
\hline & \multicolumn{2}{c}{ Dose rate/eV ml ${ }^{-1} \mathrm{~s}^{-1}$} \\
\cline { 2 - 3 } & \multicolumn{1}{c}{$1.00 \times 10^{14}$} & \multicolumn{1}{c}{$1.00 \times 10^{15}$} \\
\hline$\sigma / \Omega^{-1} \mathrm{~cm}^{-1}$ & $1.22 \times 10^{-12}$ & $4.15 \times 10^{-12}$ \\
$\tau / \mathrm{s}$ & 0.175 & 0.0514 \\
$R_{\mathrm{p}} / \mathrm{M} \mathrm{s}^{-1}$ & $6.4 \times 10^{-4}$ & $2.6 \times 10^{-3}$ \\
$k_{\mathrm{p}} / \mathrm{M}^{-1} \mathrm{~s}^{-1}$ & $2.5 \times 10^{6}$ & $3.5 \times 10^{6}$ \\
\hline
\end{tabular}

such as hexane and cyclohexane is about 0.1 . A freeion lifetime, $\tau$, for the system in which there exist only two kinds of ions, i.e., negative and positive charge carrier whose mobilities are expressed as $\mu_{-}$ and $\mu_{+}$, respectively, is considered. A stationary state is then defined by the equation,

$$
\frac{I G_{\mathrm{i}}}{100}=R_{\mathrm{i}}=k C^{2}
$$

where $I$ is the dose rate, $R_{\mathrm{i}}$ the rate of ion production, $k$ the rate constant of bimolecular recombination of ions and $C$ the concentration of free ions. $\tau$ is calculated from the special electrical conductivity, $\sigma$, using the following equations.

$$
\begin{aligned}
& \sigma=e\left(\mu_{+}+\mu_{-}\right) C \\
& \tau=\frac{C}{R_{\mathrm{i}}}=\frac{\varepsilon}{4 \pi \sigma}
\end{aligned}
$$

where $e$ is the unit of electronic charge. The calculated lifetimes $\tau$ of charge carriers in irradiated liquids are summarized in Table II. On the other hand, the rate of polymerization is related to the free-ion lifetime $\tau$, through the equation,

$$
R_{\mathrm{p}}=R_{\mathrm{i}} \tau k_{\mathrm{p}}[\mathrm{M}]
$$

where $k_{\mathrm{p}}$ is propagation-rate constant and [M] concentration of monomer.

Electrical-conductivity measurement was carried 
Radiation and Photo-Induced Ionic Polymerization

Table IV. Propagation rate constants in addition polymerization of styrene

\begin{tabular}{|c|c|c|c|c|}
\hline \multirow{2}{*}{ Catalyst } & \multirow{2}{*}{ Solvent } & Temp & \multirow{2}{*}{$\frac{k_{\mathrm{p}}}{\mathrm{M}^{-1} \mathrm{~s}^{-1}}$} & \multirow{2}{*}{$\begin{array}{c}\text { Reference } \\
\text { No. }\end{array}$} \\
\hline & & ${ }^{\circ} \mathrm{C}$ & & \\
\hline Radiation, free cation & Bulk & 15 & $3.5 \times 10^{6}$ & 17 \\
\hline $\mathrm{Bu}_{4} \mathrm{~N}^{+} \mathrm{CF}_{3} \mathrm{SO}_{6}{ }^{-}$, free cation & $\mathrm{C}_{2} \mathrm{H}_{4} \mathrm{Cl}_{2}$ & 30 & $3.0 \times 10^{6}$ & 23 \\
\hline Free anion & $\mathrm{THF}^{\mathrm{a}}$ & 25 & $6.5 \times 10^{4}$ & 24 \\
\hline Free radical & Bulk & 20 & 35 & 25 \\
\hline \multicolumn{5}{|l|}{ Cationic ion-pair } \\
\hline $\mathrm{H}_{2} \mathrm{SO}_{4}$ & $\mathrm{C}_{2} \mathrm{H}_{4} \mathrm{Cl}_{2}$ & 25 & 7.7 & 26 \\
\hline $\mathrm{SnCl}_{4}$ & $\mathrm{C}_{2} \mathrm{H}_{4} \mathrm{Cl}_{2}$ & 25 & 0.41 & 27 \\
\hline $\mathrm{Bu}_{4} \mathrm{~N}^{+} \mathrm{CF}_{3} \mathrm{SO}_{3} \mathrm{H}$ & $\mathrm{C}_{2} \mathrm{H}_{4} \mathrm{Cl}_{2}$ & 30 & $1.2 \times 10^{5}$ & 23 \\
\hline
\end{tabular}

a THF, tetrahydrofuran.

out on dried styrene. According to eq 35 , the estimation of $k_{\mathrm{p}}$ rests on a knowledge of $R_{\mathrm{p}}, \tau$, and $R_{\mathrm{i}}$ at a particular dose rate. In the calculations of Table III, $R_{\mathrm{p}}$ values are determined dilatometrically and $R_{\mathrm{i}}$ is based on a $G_{\mathrm{i}}$ value of 0.1 for nonpolymerizable hydrocarbons. It should be noted that the lifetime of free ions under irradiation at these dose rates is of the order of $100 \mathrm{~ms}$ and $k_{\mathrm{p}}$ values of free cationic propagation are very large, as high as $10^{6} \mathrm{M}^{-1} \mathrm{~s}^{-1}$. The values obtained for $k_{\mathrm{pc}}$ in Table III are considered as lower limits owing to the impurity effect. On the other hand, the determination by the amine retardation method should set an upper limit to $k_{\mathrm{pc}}$ of about $4 \times 10^{8}$ $\mathrm{M}^{-1} \mathrm{~s}^{-1}$ but the reliability of the value is questionable because of experimental difficulties. Consequently, more confidence is attached to the determination by the conductivity method, $k_{\mathrm{pc}}>3.5 \times 10^{6} \mathrm{M}^{-1} \mathrm{~s}^{-1}$, and it is unlikely that the limiting value of $k_{\mathrm{pc}}$ exceeds $10^{7} \mathrm{M}^{-1} \mathrm{~s}^{-1}$, since the observed dose-rate dependence of $R_{\mathrm{p}}$ is so close to 0.5 .

The propagation-rate constants derived from this study are summarized and compared in Table IV with the values obtained in other work under a variety of conditions and with different catalyst systems.

It is clear that the rate constants for both free cation and free anion are much larger than freeradical or ion-pair propagation. Moreover, the $k_{\mathrm{p}}$ for the free cation appears to be at least 50 times greater than that for the free anion.

Ka. Hayashi et al. ${ }^{17}$ reported the estimation of free-ion lifetimes by pulse electrical-conductivity measurement based on the principle of the "rotating sector method" which is used for lifetime estimation of intermediates generated by photoillumination through bimolecular reaction. The estimated lifetimes agreed with those calculated from steadystate conductance.

The preexponential factor $A_{\mathrm{p}}$ is about $10^{8} \mathrm{M}^{-1}$ $\mathrm{s}^{-1}$ for free carbonium-ion polymerization, which is fairly close in value to that for free-radical propagation $\left(A_{\mathrm{p}}=2.2 \times 10^{7} \mathrm{M}^{-1} \mathrm{~s}^{-1}\right)$. Hence the much lower rate constants for free-radical propagation are due to the high activation energy. For the cation pairs an appreciable activation energy appears to be involved in some instances, and $A_{\mathrm{p}}$ values are also decreased from the free-ion value, depending upon the extent to which the free rotation of the incoming monomer unit is restricted by the counter-ion in the transition state.

The temperature dependence of the rate of polymerization appears to be more complicated and the rates do not fit a simple Arrhenius relationship since there appears to be a maximum value at about $30^{\circ} \mathrm{C}$. A change in temperature may effect the effective concentration of adventitous retarders if these are composed of aggregates of water molecules. Szwarc et al. ${ }^{28}$ has reported $5.9 \mathrm{kcal} \mathrm{mol}^{-1}$ of activation energy for the polymerization of styrene in tetrahydrofuran by a free anionic mechanism, and this is understandable in terms of the solvation of growing free anions by solvent molecules. The propagation reaction of styrene by a free cationic process in bulk is characterized by a lower activation energy. ${ }^{29}$

In complete contrast to the effect of trimethyl- 


\section{K. HAYASHI}

amine, the addition of nitrous oxide and dichloromethane, which have high electron affinities, had little effect on the polymerization rate. ${ }^{30}$

The molecular weight of the polystyrene formed by the ionic mechanism is also limited by monomer chain-transfer to $\overline{D P} \simeq 500$ even in the case of extremely high rates of polymerization. This reaction is interpreted by the proton-transfer mechanism.

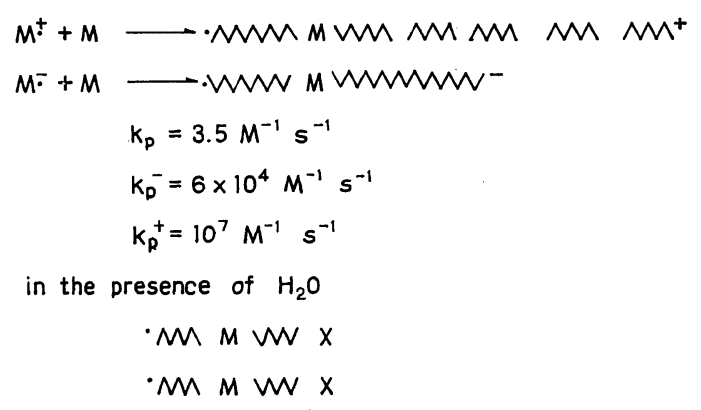

Figure 8. General reaction scheme of radiationinduced polymerization.

Summarizing the results obtained, the general reaction scheme of this polymerization is represented in Figure 8. That is, under irradiation three different active species of radical, cation and anion initiate the chain-growing reaction. However, the relative rate of propagation by the cation mechanism is the highest among them. Consequently, only the polymerization which proceeds by a cationic mechanism can be obtained. In the presence of a small amount of impurity such as water, the ionic propagations are suppressed and the radical polymerization appears at a considerably lower rate. As mentioned above, $k_{\mathrm{p}}$ value was evaluated as $\sim 10^{6} \mathrm{M}^{-1} \mathrm{~s}^{-1}$ and $[\mathrm{M}]=10 \mathrm{M}$, the time of one step of propagation is estimated to be $10^{-7} \mathrm{~s}$. As the kinetic chain length is $10^{7}$ because $G_{\mathrm{i}}=0.1$ and $G(-M)=10^{6}$, the lifetime of growing cation, that is the time from initiation until the termination is estimated to be $10^{-1} \mathrm{~s}$.

Molecular-weight distribution (MWD) studies by gel-permeation chromatography of the radiationinduced polymerization of styrene in the presence of suitable amounts of water indicated the presence of two peaks, which are caused by the coexistence of two propagating species, radical and cationic. ${ }^{31}$

Particular importance has been attached to the

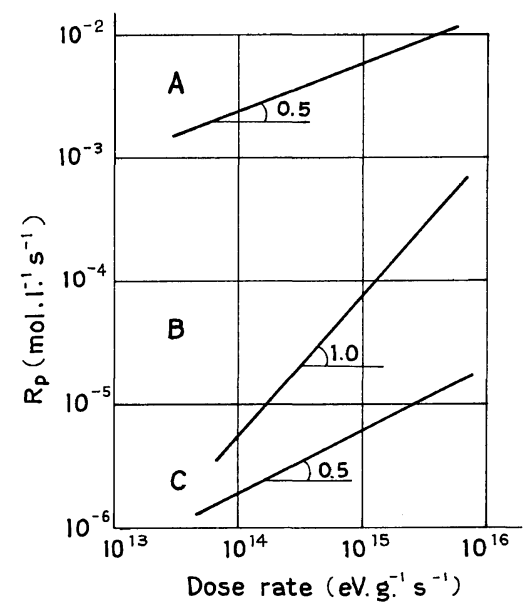

Figure 9. The rate of radiation-induced polymerization of styrene as a function of dose rate under different conditions.

dose rate dependence of the rate of polymerization as a function of impurity concentration. Curve $A$ of Figure 9 represents the rate of polymerization of

styrene in the absence of impurity in which a bimolecular termination reaction takes place between growing cations and free anions existing in the system. In the presence of impurities with concentration in the range of $10^{-7} \sim 10^{-6} \mathrm{M}$ (curve B), the rate of cationic polymerization is reduced owing to the impurity termination which is believed to be an apparent monomolecular reaction.

The chain-transfer mechanism of cationic polymerization of $\alpha$-methylstyrene has been studied in the presence of several aliphatic hydrocarbons. According to eq 36 , the $k_{\mathrm{ts}} / k_{\mathrm{p}}$ value has been determined.

$$
(\overline{D P})^{-1}=k_{\mathrm{tm}} / k_{\mathrm{p}}+\left(k_{\mathrm{ts}} / k_{\mathrm{p}}\right)[\mathrm{S}] /[\mathrm{M}]
$$

where $k_{\mathrm{tm}}$ and $k_{\mathrm{ts}}$ are rate constants of chain transfer to monomer and to solvent, respectively. Among $\mathrm{C}_{6}$ hydrocarbons the $k_{\mathrm{ts}} / k_{\mathrm{p}}$ value increases in the order: 2,2-dimethylbutane $<$ 2,3-dimethylbutane $<$ hexane $\simeq 3$-methylpentane. The relative reactivity increased in the order: primary $<$ secondary $<$ tertiary hydrogens. The result is consistent with the view that the chain transfer is the hydride ion transfer

$$
\begin{aligned}
& \mathbf{M}^{+}+\mathrm{RH} \rightarrow \mathrm{MH}+\mathrm{R}^{+} \\
& \mathrm{R}^{+}+\mathrm{M} \rightarrow \mathrm{RM}^{+}
\end{aligned}
$$


from the solvent molecule to the propagating cation. The low reactivity of primary hydrogen is also demonstrated by the low $k_{\mathrm{ts}} / k_{\mathrm{p}}$ value of neopentane. ${ }^{44}$

\section{RADIATION-INDUCED IONIC POLYMERIZATION IN THE PRESENCE OF ELECTRON ACCEPTOR}

The addition of a small amount of PMDA (piromellitic dianhydride) results in an appreciable increase in the polymer yield of radiation-induced ionic polymerization of $\alpha$-methylstyrene. ${ }^{32}$ At $-78^{\circ} \mathrm{C}$, the polymer yield increased by a factor of $7-8$ at $2.0 \mathrm{M}$ of monomer concentration in dichloromethane in the presence of PMDA $\left(\sim 10^{-3} \mathrm{M}\right)$. The MWD is bimodal in the presence of PMDA, indicating the existence of two types (free ion and ion pair) of propagating species possessing different reactivities. The lower molecular weight peak of the bimodal distribution coincides in position with the peak of the polymer obtained in the absence of PMDA and can be assigned to the free-ion polymerization. It is considered that the propagating species producing the higher molecular weight polymer is also cationic, since the contribution of other propagating species such as a radical and an anion can be ruled out.

The use of electron-beam accelerator which is generally capable of providing a dose rate of $10^{4}-$ $10^{6} \mathrm{rad} \mathrm{s}^{-1}$ provided a new method of rapid polymerization which is available for many practical purposes. From the kinetic point of view, a steady-state equation in radical polymerization indicates that $R_{\mathrm{p}}$ increases proportionally to the square root of dose rate while molecular weight of the product decreases with increasing dose rate. In cationic polymerization eq 22 and 28 indicate that $R_{\mathrm{p}}$ is a function of dose rate and [X] but the molecular weight is independent of dose rate. From eq 28 it is easily understood that there are two ways to approach the ultimate relationship, $R_{\mathrm{p}} \propto I^{1 / 2}$; to decrease $[\mathrm{X}]$ by rigorous drying or to use high dose rate. Therefore, it is expected that in high dose-rate polymerization we can save trouble of drying monomer to some extent.

The first significant work in this field was made by Stannett and coworkers. ${ }^{33}$ They reported that with bulk styrene $R_{\mathrm{p}}$, at high dose rate deviated from the half-power dependence to dose rate while the number-average molecular weight at high dose rate keeps almost constant value. This was well explained with polymerization by two concurrent mechanisms, radical and cationic and with the increase of dose rate, the latter mechanism became predominant. Later, from the analyse of molecular weight distributions of polystyrenes, Takezaki et $a l .{ }^{34}$ proposed that two more subsidary mechanisms were also coexisting corresponding to the formation of oligomer and high-molecular-weight product of ca. $10^{6}$. They also studied the variations of the $R_{\mathrm{p}}$ and molecular weight distributions for each mechanisms as a function of dose rate $e^{34}$ and water content. ${ }^{34}$

\section{RADICAL-INDUCED IONIC POLYMERIZATION}

Oxidation of free radicals results in the formation of corresponding carbocations, while reduction of free radicals forms carbanions.

$$
\begin{aligned}
& \mathrm{R} \cdot+\mathrm{A} \rightarrow \mathrm{R}^{+}-\mathrm{A}^{-} \\
& \mathrm{R} \cdot+\mathrm{D} \rightarrow \mathrm{R}^{-}+\mathrm{D}^{+}
\end{aligned}
$$

In principle, we can expect to produce carbocations, which is capable of initiating cationic polymerizations, from radiation- or photo-generated free radicals in the presence of suitable electron acceptors.

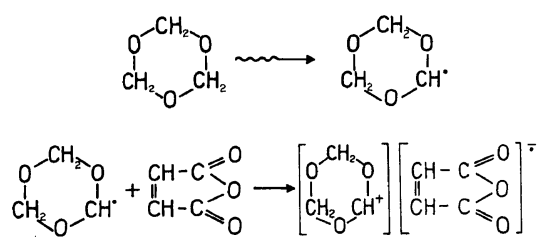

Figure 10. Radical-initiated cationic polymerization of trioxane in the presence of maleic anhydride. ${ }^{35,36}$

Isobutyl vinyl ether, 1,2-butylene oxide, trioxane, and 3,3-bis(chloromethyl)oxetane were found to be polymerized in the presence of maleic anhydride. $^{35-36}$

Most of the maleic anhydride remained unaltered after polymerization was completed. This polymerization is inhibited by the addition of a small amount of radical scavengers, thus suggesting a 
Table V. Radiation-induced cationic polymerization of $\alpha$-methylstyrene via dichloromethane ${ }^{\mathrm{a}}$

\begin{tabular}{|c|c|c|c|c|c|c|c|c|c|}
\hline \multirow[t]{2}{*}{ Initiation } & $\begin{array}{l}\text { Reaction } \\
\text { time }\end{array}$ & $\begin{array}{c}\text { Salt } \\
\text { concn }\end{array}$ & & $\begin{array}{l}\mathrm{AIBN}^{\mathrm{b}} \\
\text { concn }\end{array}$ & $\begin{array}{l}\text { Monomer } \\
\text { concn }\end{array}$ & $\begin{array}{l}\text { Conven- } \\
\text { tion }\end{array}$ & $\begin{array}{c}G \\
\times\end{array}$ & $M_{n}$ & $M_{w}$ \\
\hline & $\min$ & $\mathrm{mg} \mathrm{ml}^{-1}$ & & $\mathrm{mg} \mathrm{ml}^{-1}$ & M & & & & \\
\hline$\gamma$-Ray & 20 & $\left(\mathrm{C}_{6} \mathrm{H}_{5}\right)_{3} \mathrm{SPF}_{6}$ & 25 & - & 3.87 & 33.42 & 4200 & $2.8 \times 10^{4}$ & $4.0 \times 10^{4}$ \\
\hline$\gamma$-Ray & 20 & $\left(\mathrm{C}_{6} \mathrm{H}_{5}\right)_{3} \mathrm{SAsF}_{6}$ & 25 & - & 3.87 & 10.45 & 1300 & $3.0 \times 10^{4}$ & $4.0 \times 10^{4}$ \\
\hline$\gamma$-Ray & 20 & - & & - & 3.87 & 0 & - & - & - \\
\hline Photo & 30 & $\left(\mathrm{C}_{6} \mathrm{H}_{5}\right)_{3} \mathrm{SPF}_{6}$, & 25 & 10 & 3.87 & 2.93 & - & $2.6 \times 10^{4}$ & $3.4 \times 10^{4}$ \\
\hline Photo & 30 & $\left(\mathrm{C}_{6} \mathrm{H}_{5}\right)_{3} \mathrm{SAsF}_{4}$, & 25 & 10 & 3.81 & 5.58 & - & $2.8 \times 10^{4}$ & $3.6 \times 10^{4}$ \\
\hline Photo & 30 & - & & 10 & 3.81 & 0 & - & - & - \\
\hline
\end{tabular}

a $\mathrm{CaH}_{2}$, dry, $0^{\circ} \mathrm{C} ; \mathrm{I}=5 \times 10^{5} \mathrm{r} \mathrm{h}^{-1}$; solvent, $\mathrm{CH}_{2} \mathrm{Cl}_{2}$.

b Azobisisobutyronitrile.

radical initiating mechanism. Polymerization mechaism in the presence of maleic anhydride is considered as follows.

$$
\begin{aligned}
& \mathrm{I} \stackrel{h v, \gamma}{\longrightarrow} \mathrm{R} \cdot \\
& \mathrm{R} \cdot+\mathrm{MAH} \longrightarrow \mathrm{R}^{+}+\mathrm{MAH}^{-} \\
& \mathrm{R}^{+}+\mathrm{M} \longrightarrow \text { Polymer }
\end{aligned}
$$

Recently there has been a growth of interest in the use of diaryliodonium salt $\left(\mathrm{Ar}_{2} \mathrm{I}^{+} \mathrm{X}^{-}\right)$, triarylsulfonium salts $\left(\mathrm{Ar}_{3} \mathrm{~S}^{+} \mathrm{X}^{-}\right)$and triarylselenonium salts $\left(\mathrm{Ar}_{3} \mathrm{Se}^{+} \mathrm{X}^{-}\right)$as photochemical initiator for cationic polymerizations. ${ }^{38,39}$ It is suggested by Ledwith ${ }^{37}$ that electron transfer to these cations results in fragmentation with the formation of ary radicals and if the reducing species is a suitable free radical, a chain reaction for formation of cation will occur.

We carried out radiation-induced polymerization of $\alpha$-methylstyrene in dichloromethane and bulk cyclohexene oxide in the presence of triphenyliodonium salt $\left(\left(\mathrm{C}_{6} \mathrm{H}_{5}\right)_{2} \mathrm{I}^{+} \mathrm{PF}_{6}{ }^{-}\right){ }^{*, 43}$ Polymerization of these monomers was observed in the presence of these salts $(G(-M) \simeq 1300)$, while no polymer was obtained in the absence of salts. ${ }^{* *}$ Postpolymerization was negligibly small. This polymerization is considered to be initiated by the reaction of free radicals produced by radiation with cation salts and to proceed in cationic mechanism,

* These salts were kindly supplied from $3 \mathrm{M}$ and G.E. Companies, U.S.A.

** The system was dried by calcium hydride and oxygen was removed by freeze-thaw method.
Table VI. Radiation-induced polymerization of bulk

\begin{tabular}{|c|c|c|c|c|}
\hline \multirow{2}{*}{$\begin{array}{c}\text { Initia- } \\
\text { tion }\end{array}$} & \multirow{2}{*}{$\frac{\text { Time }}{\min }$} & \multirow{2}{*}{$\frac{\text { Salt }}{0.2 \mathrm{M}}$} & \multirow{2}{*}{$\begin{array}{c}\begin{array}{c}\text { Conver- } \\
\text { sion }\end{array} \\
\%\end{array}$} & \multirow[t]{2}{*}{$G(-M)$} \\
\hline & & & & \\
\hline$\gamma$ & 60 & $\left(\mathrm{C}_{6} \mathrm{H}_{5}\right)_{3} \mathrm{~S}^{+} \mathrm{PF}_{6}^{-}$ & 35.6 & 5800 \\
\hline$\gamma^{\mathrm{b}}$ & 60 & $\left(\mathrm{C}_{6} \mathrm{H}_{5}\right)_{3} \mathrm{~S}^{+} \mathrm{PF}_{6}^{-}$ & 37.0 & 6000 \\
\hline$\gamma$ & 60 & $\left(\mathrm{C}_{6} \mathrm{H}_{5}\right)_{3} \mathrm{I}^{+} \mathrm{AsF}_{6}^{-}$ & 52.1 & 8500 \\
\hline$\gamma$ & 60 & $\left(\mathrm{C}_{6} \mathrm{H}_{5}\right)_{3} \mathrm{~S}^{+} \mathrm{AsF}_{6}^{-}$ & 54.3 & 8900 \\
\hline$\gamma$ & 60 & $\left(\mathrm{C}_{6} \mathrm{H}_{5}\right)_{2} \mathrm{I}^{+} \mathrm{PF}_{6}^{-}$ & 63.4 & 10300 \\
\hline$\gamma$ & 60 & None & 0 & 0 \\
\hline
\end{tabular}
cyclohexene oxide in the presence of triphenyl iodonium salt ${ }^{\mathrm{a}}$

a Temp, $0^{\circ} \mathrm{C}$; in vacuo; $\mathrm{CaH}_{2}$, dry $; M_{n} \simeq 2 \times 10^{4}$; [Salt], $0.2 \mathrm{M}$.

b Post $24 \mathrm{~h}$ at $0^{\circ} \mathrm{C}$.

since $\alpha$-methylstyrene polymerized by ionic mechanism but hardly polymerizes by radical mechanism.

The radiation-induced polycondensation of ureaformaldehyde aqueous solutions in the presence of alkyl halides has been studied. ${ }^{40}$

As it is well known, under radiation the alkyl halides decompose generating hydrogen halide which can catalyze the polycondensation reaction. After our experiments it has been ascertained that, due to mutual solubilities, the best results were obtained in the presence of chloral hydrate. ${ }^{41}$

High polymer yields were obtained at relatively low irradiation doses.

During the reaction large amounts of oligomers are formed and their concentration decreases 
increasing the reaction time.

A large post-effect is present. In this case the $G$ value for polymer formation is equal to $1.5 \times 10^{5}$, referred to the energy absorbed from the chloral hydrate and $2.9 \times 10^{3}$ referred to the energy absorbed from the whole system (Figure 11). The polymer is a white powder that has been characterized by conventional methods.
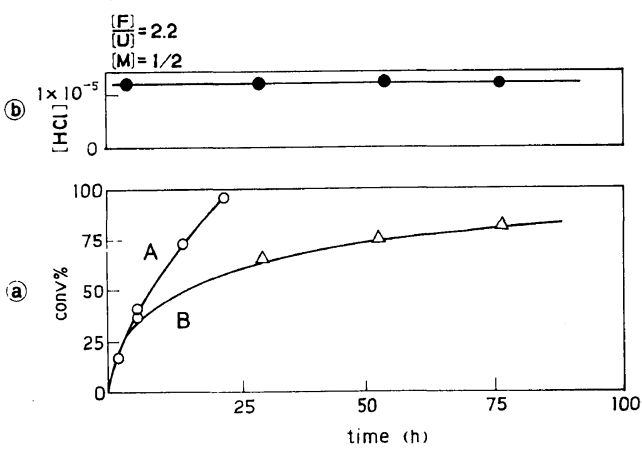

Figure 11. Radiation-induced polycondensation, postpolymerization: ${ }^{41} \mathrm{~A}$, in-sornce polymerization; $\mathrm{B}$, postpolymerization; $[\mathrm{F}] /[\mathrm{U}]=2.2 ;[\mathrm{M}]=1 / 2$.

\section{PHOTO-INDUCED IONIC POLYMERIZATION ${ }^{45}$}

We have found for the first time a photo-induced cationic polymerization of $\alpha$-methylstyrene which is a weak electron donor and contains no hetero atom, in the presence of electron acceptor such as tetracyanobenzene (TCNB) or pyromellitic dianhydride (PMDA). Extremely well dried $\alpha$-methylstyrene polymerized in dichloromethane at $-30^{\circ} \mathrm{C}$ under photoillumination of charge-transfer band of $\alpha$-MS-TCNB complex, though no polymer was obtained in the dark. The effect of cationic inhibitors and copolymerization with styrene indicate that the polymerization proceeds by a cationic mechanism. In ionic polymerization, the dependence of the rate of polymerization, $R_{\mathrm{p}}$, on the light intensity, $I$, can give information on the form of the propagating-chain ends, i.e., whether they are free ion or ion-pairs. In the case where the polymerization process by free ion is not terminated by an impurity, the dependence should be $R_{\mathrm{p}} \propto I^{1 / 2}$. For ion-pairs, the dependence is expressed by $R_{\mathrm{p}} \propto I$. The dependence decreased from the first order at $-15^{\circ} \mathrm{C} ;[\mathrm{M}], 1.9 \mathrm{M}$ to 0.67 at $-74^{\circ} \mathrm{C} ;[\mathrm{M}], 0.53 \mathrm{M}$. The result suggests that free growing-chain ends also contribute to the propagation process at lower temperature. The molecular weight distributions of the polymer formed has a bimodal distribution, which clearly indicates that two chain ends with different structures propagate independently. The light-intensity dependence of the photocurrents was 0.5 at any temperature. The ions responsible for the current are free ions and recombine with each other randomly. The photocurrent, which corresponds to the concentration of free ions, increased with decreasing temperature, as expected. It also increased with decrease in the concentration of $\alpha$ methylstyrene in the system, which increases the polarity of the system. We estimated the propagation-rate constant from the above photocurrent value and the rate of polymerization measured by dilatometry. $k_{\mathrm{p}}(+)$ was obtained $(3.5 \pm 1.8) \times 10^{3} \mathrm{M}^{-1} \mathrm{~s}^{-1}$ at $-74^{\circ} \mathrm{C}$. This value is one order less than that of free ions obtained in radiation-induced ionic polymerization in bulk, even when extrapolated to room temperature by taking an activation energy of $4 \mathrm{kcal} \mathrm{mol}^{-1}$. The part of decrease is possibly due to solvation of the propagating-chain ends by polar solvent.

Acknowledgment. The author wishes to thank Professors and Doctors S. Okamura, F. Williams, M. Irie, Y. Yamamoto and all colleagues who collaborated with this work.

\section{REFERENCES}

1. W. H. T. Davison, S. H. Pinner, and R. Worrall, Chem. Ind. (London), 1274 (1957), Proc. R. Soc., London, Ser. A, 252, 187 (1959).

2. K. Hayashi, "Actions Chimiques et Biologiques des Radiation," Vol. 15, Masson \& Ed., Paris, 1971, p 145.

3. V. Stannett, H. Kubota, W. C. Hsieh, and D. R. Squise, Polym. Prepr., Am. Chem. Soc., Div. Polym. Chem., 383 (1979).

4. A. Chapiro, "Radiation Chemistry on Polymeric Systems," Intersciences Publishers, New York, N.Y., \& London, 1961, p 57.

5. Ff. Williams and K. Hayashi, Nature, 212, 281 (1966).

6. D. J. Metz and C. L. Johnson, Polym. Prepr., Am. Chem. Soc., Div. Polym. Chem., 4, 440 (1963).

7. K. Hirota and F. Takemura, Bull. Chem. Soc. Jpn., 


\section{K. HAYASHI}

35, 1037 (1962).

8. K. Ueno, K. Hayashi, and S. Okamura, J. Polym. Sci., B, 3, 363 (1965).

9. D. S. Ballantine, P. Colombo, A. Glines, and B. Manowitz, Chem. Eng. Prog., 50, 267 (1954).

10. A. Chapiro and P. Wahl, Compt. Rend., 238, 1803 (1954).

11. K. Ueno, K. Hayashi, and S. Okamura, Polymer, 7, 431 (1966).

12. K. Ueno, F. Williams, K. Hayashi, and S. Okamura, Trans. Faraday Soc., 63, 1478 (1967).

13. R. C. Potter, R. H. Bretton, and D. J. Metz, J. Polym. Sci., A-1, 4, 2295 (1966).

14. F. Williams, Ka. Hayashi, K. Ueno, K. Hayashi, and S. Okamura, Trans. Faraday Soc., 63, 1501 (1967).

15. A. Hummel and S. O. Allen, Discuss. Faraday Soc., 36, 95 (1963).

16. G. R. Freeman, J. Chem. Phys., 39, 988 (1963).

17. Ka. Hayashi, T. Takagaki, K. Takada, K. Hayashi, and S. Okamura, Bull. Chem. Soc. Jpn., 41, 1261 (1968).

18. F. Williams, Ka. Hayashi, K. Ueno, K. Hayashi, and S. Okamura, Trans. Faraday Soc., 63, 1501 (1967).

19. K. Ueno, K. Hayashi, and S. Okamura, Polymer, 7, 431 (1966).

20. K. Ueno, F. Williams, K. Hayashi, and S. Okamura, Trans. Faraday Soc., 63, 1478 (1967).

21. Ka. Hayashi, Y. Yamazawa, T. Takagaki, F. Williams, K. Hayashi, and S. Okamura, Trans. Faraday, Soc., 63, 1489 (1967).

22. F. Williams, Ka. Hayashi, K. Ueno, K. Hayashi, and S. Okamura, Trans. Faraday, Soc., 63, 1501 (1967).

23. T. Kunitake and K. Takarabe, J. Polym. Sci., Polym. Symp., No. 56, 33 (1976); Preprints, 5th International Symposium on Cationic and Other Ionic Polymerizations, Kyoto, April 15-18, 1980, p 30.

24. D. N. Bhattacharyya, C. L. Lee, J. Smid, and M. Szwarc, J. Phys. Chem., 69, 612 (1951).

25. M. S. Matheson, E. E. Auer, E. B. Bevilaqua, and E. J. Hart, J. Am. Chem. Soc., 73, 1700 (1951).
26. M. J. Hayes and D. C. Pepper, Proc. R. Soc., London Ser. $A$, 273, 63 (1961).

27. N. Kanoh, T. Higashimura, and S. Okamura, Kobunshi Kagaku, 19, 181 (1962).

28. T. Shimomura, K. J. Tolle, J. Smid, and M. Szwarc, J. Am. Chem. Soc., 89, 796 (1967).

29. Ka. Hayashi, K. Hayashi, and S. Okamura, Ann. Rep. Osaka Lab. Rad. Chem., (JAERI, 5026), 3, 169 (1970).

30. K. Ueno, K. Hayshi, and S. Okamura, J. Polym. Sci., B, 6, 39 (1968).

31. R. Y. M. Huang and J. F. Westlake, J. Polym. Sci., $A-1,8,49$ (1970).

32. Y. Yamamoto, A. Morinaka, M. Irie, and K. Hayashi, Macromolecules, 10, 266 (1977).

33. D. R. Squire, J. A. Cleaveland, T. M. A. Hossain, W. Orasy, E. P. Stabel, and V. T. Stannett, J. Appl. Polym. Sci., 16, 645 (1972).

34. J. Takezaki, T. Okada, and I. Sakurada, J. Appl. Polym. Sci., 22, 2683 and 3311 (1978).

35. K. Takakura, K. Hayashi, and S. Okamura, $J$. Polym. Sci., B, 2, 861 (1964).

36. K. Takakura, K. Hayashi, and S. Okamura, $J$. Polym. Sci, A-1, 4, 1731 and 1747 (1966).

37. A. Ledwith, Polymer, 19, 1217 (1978).

38. J. V. Crivello and J. H. W, Lam, Macromolecules, 10, 1307 (1977).

39. J. V. Crivello and J. H. W. Lam, J. Polym. Sci. Polym. Chem. Ed., 17, 1047 (1979).

40. I. Kaetsu, K. Hayashi, and S. Okamura, $J$. Macromol. Sci., Chem., A2, 1271 (1968).

41. K. Hayashi, S. Munari, C. Rossi, and C. Uliana, Chim. Ind. (Milan), 56, 264 (1974).

42. K. Hayashi, D. Lindenau, W. Schnabel, and M. Irie, J. Phys. Chem., 80, 2807 (1976).

43. Y. Yamamoto, M. Miki and K. Hayashi, unpublished results.

44. Y. Yamamoto, M. Miki and K. Hayashi, Rad. Phys. Chem., in press.

45. M. Irie and K. Hayashi, Prog. Polym. Sci., Jpn., 8, 105 (1975). 